\title{
Evaluation of Sampling Methodology for Determining the Population Dynamics of Onion Thrips (Thysanoptera: Thripidae) in Ontario Onion Fields
}

Author(s): J. K. Macintyre-Allen, C. D. Scott-Dupree, J. H. Tolman, and C. R. Harris

Source: Journal of Economic Entomology, 98(6):2272-2281. 2005.

Published By: Entomological Society of America

DOI: $10.1603 / 0022-0493-98.6 .2272$

URL: http://www.bioone.org/doi/full/10.1603/0022-0493-98.6.2272

BioOne (www.bioone.org) is an electronic aggregator of bioscience research content, and the online home to over 160 journals and books published by not-for-profit societies, associations, museums, institutions, and presses.

Your use of this PDF, the BioOne Web site, and all posted and associated content indicates your acceptance of BioOne's Terms of Use, available at www.bioone.org/page/terms_of_use.

Usage of BioOne content is strictly limited to personal, educational, and non-commercial use. Commercial inquiries or rights and permissions requests should be directed to the individual publisher as copyright holder. 


\title{
Evaluation of Sampling Methodology for Determining the Population Dynamics of Onion Thrips (Thysanoptera: Thripidae) in Ontario Onion Fields
}

\author{
J. K. MacintyRE-ALLEN, ${ }^{1}$ C. D. SCOTT-DUPREE, ${ }^{2}$ J. H. TOLMAN,${ }^{3}$ and C. R. HARRIS ${ }^{2}$
}

J. Econ. Entomol. 98(6): 2272-2281 (2005)

\begin{abstract}
Onion thrips, Thrips tabaci Lindeman, are an economic pest of alliums worldwide. In Ontario onion-growing regions, seasonal abundance and population trends of onion thrips are not well known. The objectives of this research were to investigate onion thrips population dynamics by using both white sticky traps and plant counts, to gain insight into flight height, and to determine the genus and sex of thrips fauna present in monitored fields. Adult thrips were captured on white sticky traps placed in two commercial onion fields in the Thedford-Grand Bend Marsh region as early as mid-May in 2001, 2002, and 2003. Thrips were not recorded on onion plants in these fields until late June and early July. A comparison of sticky trap captures to plant counts revealed a strong, positive correlation, indicating that sticky traps, which consistently detected thrips earlier than plant counts, could be used instead of plant counts early in the season to monitor onion thrips populations. Pole traps placed in onion and an adjacent soybean, Glycine $\max$ (L.) Merr., field revealed that regardless of crop type, most thrips were captured $0.7-0.95 \mathrm{~m}$ above the soil surface. During this study, $70 \%$ of 137,000 thrips captured on sticky traps and $89 \%$ of 1,482 thrips captured in pan traps were female onion thrips. No male onion thrips were identified in this study; most of the remaining thrips were Frankliniella spp.
\end{abstract}

KEY WORDS onion thrips, Thrips tabaci, onions, sampling

ONION THRIPS, Thrips tabaci Lindeman, is a cosmopolitan species found in onion-growing regions worldwide (Lewis 1973, Brewster 1994). They are generalists, feeding and overwintering on a diverse selection of plants and weeds (McKinlay 1992, Cho et al. 1995) and are considered a serious economic pest of onions, leeks, garlic, and shallots worldwide (Boyce and Miller 1954, Theunissen and Legutowska 1991, Brewster 1994). Although onion thrips are a major concern to growers around the world, in Ontario, their control has often been secondary to managing the onion maggot, Delia antiqua (Meigen) (Tolman et al. 1986). In recent years, however, onion thrips control has become a priority due to high infestations. Although not presently clear, it has been suggested the increase in onion thrips numbers relates to changes in onion maggot management. With the implementation of soil insecticides targeting onion maggot larvae, growers reduced or eliminated foliar sprays targeting adult onion maggots. These foliar sprays may have provided ancillary control of onion thrips. Consequently, decreased foliar sprays may have resulted in a reduction

\footnotetext{
${ }^{1}$ Ontario Ministry of Agriculture, Food and Rural Affairs, Guelph, ON N1G 4Y2, Canada.

${ }^{2}$ Department of Environmental Biology, University of Guelph, Guelph, ON N1G 2W1, Canada.

${ }^{3}$ Southern Crop Protection and Food Research Centre, Agriculture and Agri-Food Canada, London, ON N5V 4T3, Canada.
}

in selection pressure on onion thrips, leading to onion thrips proliferation.

In Ontario, the Ontario Ministry of Agriculture and Food recommends growers check at least 50-100 plants and once a threshold of three onion thrips per leaf is reached, chemical control tactics are recommended. Examples of thresholds used in the United States include 1) three onion thrips per leaf in New York state (Shelton et al. 1987); 2) one onion thrips per leaf in Texas (Edelson et al. 1989); and 3) four to 10 onion thrips per plant during two- to six-leaf stage, $10-15$ onion thrips per plant from six-leaf to maturity in Michigan (Bird et al. 2004).

Research on the effect of onion thrips feeding on onion yield has shown that as few as 10 thrips per plant during the bulbing stage of white onions can lead to a 2 to $3 \%$ bulb reduction (by weight) under field conditions and up to $7 \%$ reduction under greenhouse conditions (Kendall and Capinera 1987). Although research by Mayer et al. (1987) found no relationship between reduction in thrips populations and yield increases in Washington state, Edelson et al. (1989) concluded that to increase yields in southern Texas, insecticide applications should begin when onion thrips reach a density of only one onion thrips per plant and should continue at regular intervals. Work in Canada by Fournier et al. (1995) demonstrated that in the absence of any control measures, onion thrips infestations of yellow onions resulted in 34.5 and $43 \%$ 
yield losses during two climatically different years with seasonal averages of 149 and 172 thrips per plant respectively, in untreated plots.

To effectively control onion thrips in Ontario and realize maximal yields, it is important to understand the basic biology of the organism, to evaluate the effectiveness of monitoring strategies, and to compare current control strategies to other onion-growing regions. At this point, in Ontario, no work has been performed that permits a basic understanding of onion thrips biology. To that end, the objective of this research was to gain a better understanding of onion thrips in Ontario. To achieve this goal, three aspects of onion thrips field biology were studied: 1) population dynamics by using both white sticky traps and plant counts to determine how these monitoring methods compared, 2) determination of the genus and sex of thrips fauna present in monitored fields by using sticky and pan traps, and 3) determination of the flight height of adults thrips by using pole traps established in onion and adjacent soybean, Glycine max (L.) Merr., fields.

\section{Materials and Methods}

Study Sites. Field studies were conducted on high organic muck soil in two commercial onion fields (sites A and B) in the Thedford-Grand Bend Marsh, Ontario, in each of 2001, 2002, and 2003. In Ontario, the onion-growing season extends from the end of April beginning of May to mid-September. In 2001 and 2003, traps at sites A and B were installed in the same fields. In 2002, due to crop rotation, site A traps were installed in an onion field $\approx 70 \mathrm{~m}$ west and site $\mathrm{B}$ traps were installed in a field adjacent to those used in 2001 and 2003. Intermediate to long-day (106-112 d) dry yellow cooking onion cultivars were precision seeded the last week of April in all years at both sites. Insecticides and herbicides were applied in accordance with provincial guidelines at site A and B by the grower. At site A, insecticide applications were made the last week of July and the first and third week of August in 2001; on 12 and 22 July and 4 August 2002; and 9 and 25 July and 9 August 2003. Unfortunately, no spray records were available from site $\mathbf{B}$.

Seasonal Flight Activity Monitoring: Sticky Traps. Pasteboard traps ( 9 by $14 \mathrm{~cm}$ ) painted with Tremclad glossy white paint (Tremco Ltd., Toronto, Ontario, Canada) and inscribed with a grid $(2$ by $3 \mathrm{~cm}$ ) were used to monitor the seasonal flight activity of adult onion thrips. Although yellow traps are widely used to monitor onion maggots in Ontario, we chose to use white traps similar to those in studies by Coudriet et al. (1979) and Gangloff (1999). White-colored traps have been shown to be more attractive than yellow to onion thrips ( $\mathrm{Lu} \mathrm{1990).} \mathrm{In} \mathrm{addition} \mathrm{to} \mathrm{being} \mathrm{more}$ attractive to thrips, the use of white traps minimized the capture of onion maggots. Traps were positioned at the top of the plant canopy, stapled to a wooden stake $(2 \mathrm{~cm}$ by $4 \mathrm{~cm}$ by $1 \mathrm{~m})$ and coated with Tanglefoot bird repellent (The Tanglefoot Company, Grand Rapids, MI).
Seven sticky traps were installed in each onion field with the first trap located $40 \mathrm{~m}$ from the headlands in the hedgerow at the field edge and subsequent traps established at 10-m intervals in a line perpendicular to the field edge. For enumeration, traps were removed weekly, covered with clean plastic wrap, and returned to the laboratory for insect identification. On all sampling dates, with the exception of 3 and 10 September 2002 , all thrips captured on traps were counted and identified to species by the keys of Chiasson (1986), Mound and Kibby (1998), and Palmer et al. (1989). On 3 and 10 September, $>21,000$ thrips were captured. In an effort to estimate the species composition, three subsamples ( 3 by $2 \mathrm{~cm}$ ) were counted on each trap. Traps were installed at both sites on 15 May 2001, 14 May 2002, and 15 May 2003. Traps were removed from site A on 28 August 2001, 10 September 2002, and 18 September 2003 and from site B on 4 September 2001, 10 September 2002, and 25 September 2003.

Characterization of Genus and Sex: Pan Traps. On 20 June 2001 and 8 July 2002, one plastic pan trap (6 by $16 \mathrm{~cm}$ ) was installed at each site to facilitate thrips identification. Due to the report of the presence of both male and female onion thrips in onion fields in New York state (Gangloff 1999), all captured thrips were sexed. Each pan trap was painted with Tremclad glossy white paint (Tremco Ltd.) (Richter et al. 1999) filled with a saline solution consisting of $1 \mathrm{ml}$ of Photo Flo (Kodak, Toronto, Ontario, Canada) and water, and placed $37 \mathrm{~m}$ from the headlands and $10 \mathrm{~m}$ in from the hedgerow on the soil surface between two beds of onions. Saline solution in traps was changed weekly.

Assessment of Onion Thrips Number and Life Stage: Plant Samples. In addition to trap counts at sites $\mathrm{A}$ and $\mathrm{B}$, onion plants in these fields were sampled to assess the number and life stage of thrips present throughout the growing season. Once onion seedlings passed the flag leaf stage, seven randomly selected plants were destructively sampled weekly between each pair of sticky traps for a total of 49 plants per week per site.

Flight Height Monitoring: Pole Traps. To determine flight height of onion thrips, two pole traps were installed at site A in 2002 and 2003. Each pole trap consisted of two wooden poles $(5 \mathrm{~cm}$ by $5 \mathrm{~cm}$ by $2.4 \mathrm{~m}$ ) spliced end to end and bolted $0.15 \mathrm{~m}$ above the ground to a post anchored into the ground. White sticky traps, described in "Seasonal Density Monitoring: Sticky Traps," were installed on each pole at increasing heights above the ground: trap 1, $0.7 \mathrm{~m}$; trap 2, $0.95 \mathrm{~m}$; trap 3, $1.2 \mathrm{~m}$; $\operatorname{trap} 4,1.45 \mathrm{~m}$; $\operatorname{trap} 5,1.95 \mathrm{~m}$; $\operatorname{trap} 6,2.45 \mathrm{~m}$; trap 7, $2.95 \mathrm{~m}$; trap 8, $3.45 \mathrm{~m}$; trap 9, $3.95 \mathrm{~m}$; trap 10, $4.45 \mathrm{~m}$; and trap 11, $4.95 \mathrm{~m}$. During both years, one pole was situated $8 \mathrm{~m}$ from the edge of the onion field and the other $7.5 \mathrm{~m}$ from the edge of the adjacent soybean field. Although the pole traps were in the same line of sight, the two fields were separated by $20.5 \mathrm{~m}$.

In 2002, six sticky traps were attached to each pole on 10 July. On 22 July, due to the high numbers of onion thrips captured on trap 6, five additional traps were installed above the initial six traps. In 2003, 11 traps were attached to each pole on 9 July. All traps 
were changed weekly by lowering the pole to ground level.

Statistical Analysis. Statistical analyses were performed on pole trap data. To reduce variances on means and heterogeneity of variances among treatments, all data were transformed using $\log (1+n)$. Regression analysis (linear and quadratic) was performed to determine the relationship between onion thrips numbers and flight height (SPSS 12.0 for Windows, SPSS Inc. 2004). A comparison of regression slopes was performed by constructing $95 \%$ confidence intervals about the slope parameter. Slopes were considered significantly different if the intervals did not overlap (Neter and Wasserman 1974). In all cases, actual rather than transformed means are presented. To determine whether sticky trap data correlated to onion thrips density on plants, Spearman rank correlations on actual counts from 2001 (site A, $n=15$; site $\mathrm{B}, n=18$ ), 2002 (site $\mathrm{A}, n=17$; site $\mathrm{B}, n=17$ ), and 2003 (site A, $n=17$; site $\mathrm{B}, n=18$ ) were performed (Statistix 2.2, Statistix 2000).

\section{Results}

Seasonal Density Monitoring. Onion thrips was the predominant species captured on sticky traps during all years (Table 1). In 2002, extremely high numbers of thrips were captured during the first 2 wk of September at site A. On 3 September 2002, >21,000 thrips were captured. It was estimated that only $10 \%$ of the thrips captured were onion thrips, whereas the remaining 90\% were Frankliniella spp.. On 10 September $2002,40 \%$ of the thrips captured on traps were identified as onion thrips.

Low numbers of onion thrips were captured during the first week of trap monitoring at site A during all years and at site B during 2001 and 2002 (Fig. 1). In 2003 at site B, the first onion thrips was not captured until 4 June, 3 wk after trap installation. In 2001, the onion thrips population peaked on 14 August at both sites (Fig. la and b). On this date, twice as many onion thrips were captured at site A than at site B. In 2002 , the onion thrips population at site B first peaked on 14 August, 1 wk earlier than the population at site A. In 2003, population numbers were substantially lower than in 2001 or 2002. At site A, the onion thrips population increased on 9 July and 6 August 2003 and then declined the following week, finally peaking on 26 August (Fig. 1a). A similar trend was observed at site $\mathrm{B}$, with the onion thrips population peaking on 18 September 2003 (Fig. 1b).

Characterization of Genus and Sex. In 2001, >91\% of thrips captured in pan traps at both sites were onion thrips. At site A, 335 of 364 thrips captured were female onion thrips with the remaining 29 identified as either Frankliniella spp. or phlaeothrips (28 females and one male). At site B, 627 of 689 thrips captured were female onion thrips with the remaining 62 (58 females and four males) identified as Frankliniella spp.. In $2002,>83 \%$ of thrips captured at both sites were female onion thrips. At site A, 157 of 193 thrips captured were female onion thrips with the remaining 36 classified as Frankliniella spp. (33 females and three males). At site B, 200 of 236 thrips captured were female onion thrips and 36 Frankliniella spp. (35 females and one male). No male onion thrips were captured at either site in either year.

Assessment of Onion Thrips Numbers and Life Stage. At both sites in 2001, onion thrips (adults and nymphs) were not detected on plants until 26 June (Fig. 2), $4 \mathrm{wk}$ after the first collection of onion thrips on sticky traps. In 2002, onion thrips (adults and nymphs) were first detected on 25 June (site B) and 2 July (site A), 5 and 6 weeks, respectively, after their detection on sticky traps. On 17 June 2003, adults were detected on plants at both sites, $4 \mathrm{wk}$ after detection on sticky traps. Nymphs were not detected on plants in 2003 until 25 June (site A) and 30 June (site B). A comparison of sticky trap captures and plant counts using Spearman rank correlations revealed that in 2001, 2002, and 2003 trap captures were positively correlated with plant counts at both sites (Fig. 3).

Flight Height Monitoring. More than $87 \%$ of thrips captured on pole traps installed in onion and adjacent soybean fields in 2002 and 2003 were onion thrips (Table 2).

In 2002 and 2003, onion thrips populations peaked three and two times, respectively, during the season in both the onion and soybean fields (Fig. 4). In both years, thrips captures at all heights followed a similar

Table 1. Numbers of adult thrips collected on white sticky traps in two commercial onion fields (site A and B) at the Thedford-Grand Bend Marsh, Ontario, in 2001, 2002 and 2003

\begin{tabular}{|c|c|c|c|c|c|c|}
\hline \multirow{3}{*}{ Taxa } & \multicolumn{6}{|c|}{ Total no. of adult thrips captured (\% of total) } \\
\hline & \multicolumn{2}{|c|}{2001} & \multicolumn{2}{|c|}{2002} & \multicolumn{2}{|c|}{2003} \\
\hline & Site A & Site B & Site A & Site B & Site A & Site B \\
\hline Thrips tabaci & $27,306(85.5)$ & $11,967(72.2)$ & $21,350(44.1)$ & $18,879(64.7)$ & $9,745(82.5)$ & $7,123(88.5)$ \\
\hline Frankliniella spp. ${ }^{a}$ & $4,462(14.0)$ & $4,334(26.3)$ & $26,735^{b}(55.3)$ & $10,181(34.9)$ & & \\
\hline F. occidentalis & & & & & $1,046(8.9)$ & $475(5.9)$ \\
\hline F. tritici & & & & & $616(5.2)$ & $285(3.6)$ \\
\hline Other & $184(0.5)$ & $171(1.0)$ & $291(0.6)$ & $119(0.4)$ & $398(3.4)$ & $163(2.0)$ \\
\hline Total & 31,952 & 16,472 & 48,376 & 29,179 & 11,805 & 8,046 \\
\hline
\end{tabular}

${ }^{a}$ In 2001 and 2002, all Frankliniella species were grouped together.

${ }^{b}$ Two weeks (3 and 10 Sept.) accounted for 23,130 (86.5\%) of all Frankliniella spp. collected at site A in 2002. 
(a)

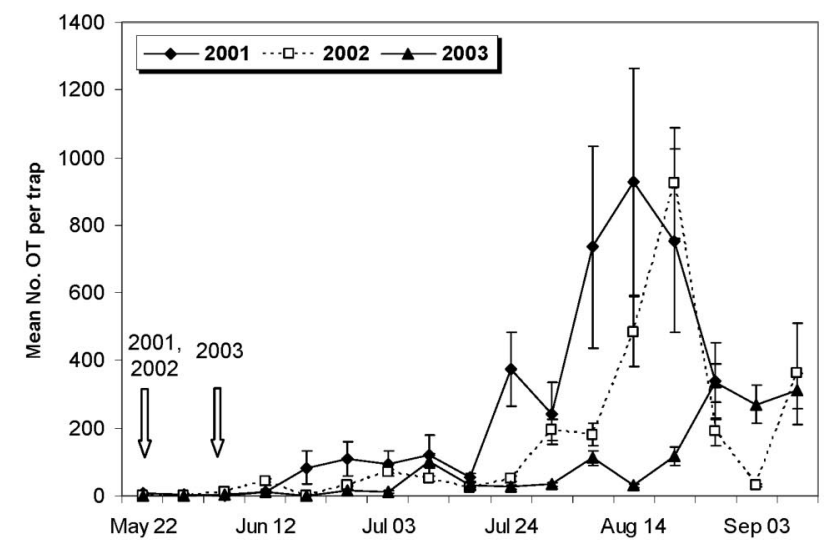

(b)

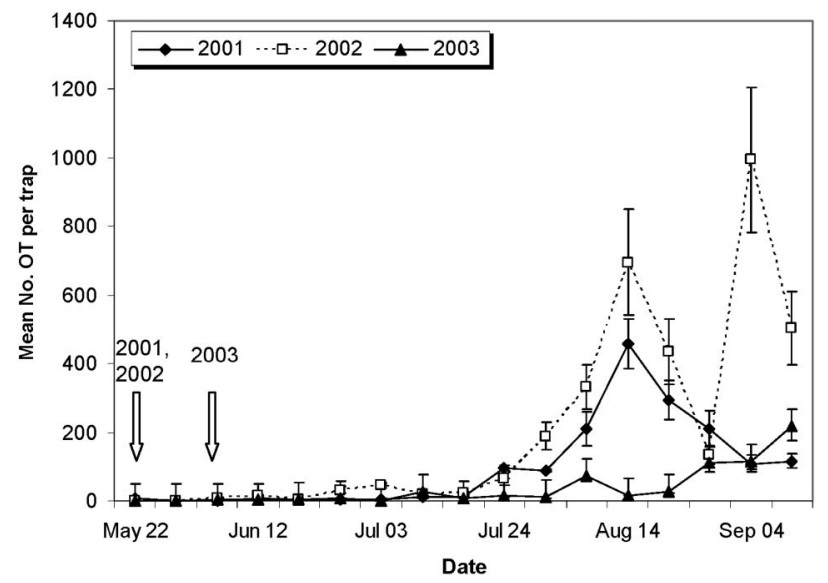

Fig. 1. Mean number of onion thrips (OT) per white sticky trap for each sample period in commercial onion fields, site A (a) and site B (b) in 2001, 2002, and 2003. Arrows indicate first thrips capture each year.

pattern throughout the growing season (Fig. 5). More thrips were captured on traps located at 0.7 and $0.95 \mathrm{~m}$ in both crops during all years of monitoring. In 2002, on average, more thrips were captured at 0.95 on the pole trap in the onion field, whereas more thrips were captured at $0.7 \mathrm{~m}$ in the soybean field. In 2003, on average, more thrips were captured at $0.7 \mathrm{~m}$ on both onion and soybean pole traps.

Regression analysis revealed that quadratic regression gave a better data fit than linear regression in onions (2002: $\mathrm{F}_{\text {linear }}=37.6$; $\mathrm{df}=1,9 ; P<0.001$; $\mathrm{F}_{\text {quadratic }}=30.1 ; \mathrm{df}=2,8 ; P<0.002 ; 2003: \mathrm{F}_{\text {linear }}=5.1$; $\left.\mathrm{df}=1,9 ; P<0.05 ; \mathrm{F}_{\text {quadratic }}=17.1 ; \mathrm{df}=2,8 ; P<0.002\right)$ and soybean $\left(2002: \mathrm{F}_{\text {linear }}=59.6 ; \mathrm{df}=1,9 ; P<0.000\right.$; $\mathrm{F}_{\text {quadratic }}=141.5 ; \mathrm{df}=2,8 ; P<0.000 ; 2003: \mathrm{F}_{\text {linear }}=$ $60.9 ; \mathrm{df}=1,9 ; P<0.000 ; \mathrm{F}_{\text {quadratic }}=501.8 ; \mathrm{df}=2,8$; $P<0.000$ ) (Fig. 6). A comparison of slopes between onions and soybean in 2002 and 2003 were not significantly different from each other (Table 3). A comparison of slopes between years for each crop revealed no significant difference in regression slope parameters between onions but a significant difference was observed between years in soybean.

\section{Discussion}

With one exception, adult onion thrips were captured on sticky traps at both sites in mid-May during all $3 \mathrm{yr}$ of monitoring. In 2003, onion thrips were not detected at site B until the first week of June. Delayed detection at this site may have been due to several factors. In 2003, an average of $35 \mathrm{~mm}$ of rain was recorded during May compared with $<2 \mathrm{~mm}$ in 2001 and 2002. The mean temperature for May 2003 was $11.8^{\circ} \mathrm{C}$ compared with 16.2 and $26.3^{\circ} \mathrm{C}$ in 2001 and 2002 , respectively. The colder, wetter spring likely accounts for lower overall onion thrips numbers at both sites. Additionally, during all $3 \mathrm{yr}$ of monitoring, the onion thrips population at site A was 1.5- to 3-fold higher than at site $\mathrm{B}$. Because onion thrips numbers at site A were $<0.2$ onion thrips per trap during the first $2 \mathrm{wk}$ of monitoring in 2003, it is not surprising that no thrips were captured during the same period at site $\mathbf{B}$.

Two distinct peaks of adult onion thrips activity on sticky traps were observed during 2001 and 2002, separated by $4 \mathrm{wk}$ at both sites. These patterns are similar to those described by Gangloff (1999) in New York state, Van de Steene (1999) in Belgium, and 

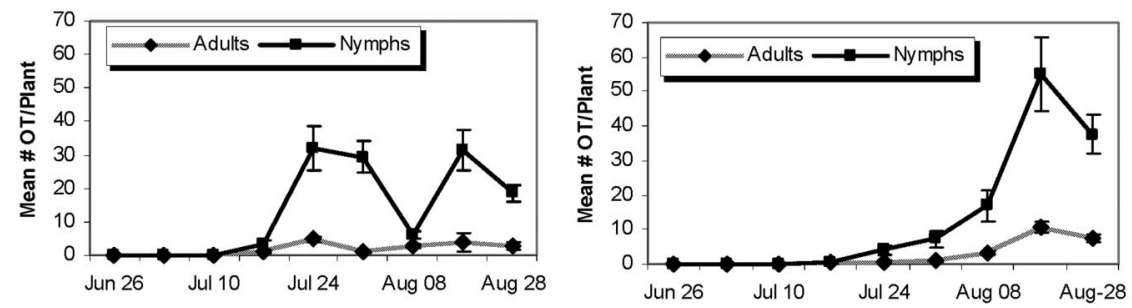

2002
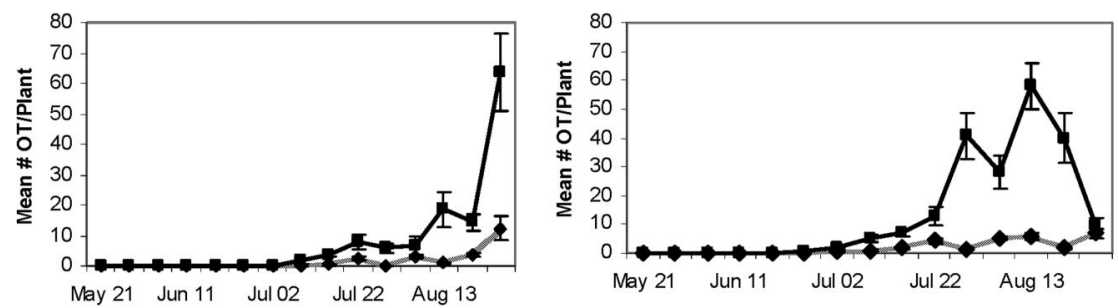

2003

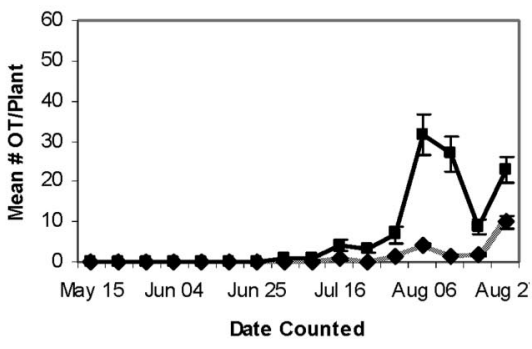

(a) Site $\mathrm{A}$

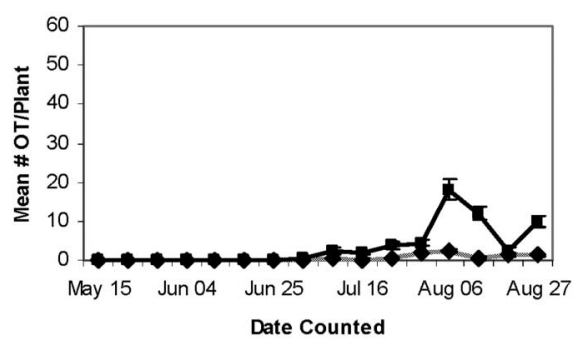

(b) Site B

Fig. 2. Mean number of adult and nymph onion thrips (OT) per onion plant for each sample period in two commercial onion fields, site A (a) and site B (b) in 2001, 2002, and 2003.

Quartey (1982) in Michigan. In 2003, three peaks were observed at site $\mathrm{A}$, whereas only two peaks were observed at site B. At site A, insecticides sprayed on 9 July and 7 August were followed by population declines on sticky traps the following weeks. Earlier application of insecticide on 9 July 2003 may have interrupted initial buildup of the thrips population, artificially generating the first peak at this site. In 2001 and 2002, the first insecticide application was not applied until mid-tolate July. This delay may have allowed thrips numbers to build up and peak later in July.

Onion thrips were the most abundant thrips species captured by sticky traps and pan traps. Frankliniella spp. were captured predominantly at the end of the growing season.

Onion thrips are a cosmopolitan species and their sex ratios differ around the world with some populations undergoing both thelotoky and arrhenotoky reproduction. The most common mode of onion thrips reproduction, especially in North America, is thelotoky parthenogenesis whereby unmated females produce only female progeny (Lewis 1973, Kendall and Capinera 1990). However, it should be noted that males have been identified in different oniongrowing regions around the world. In the Mediterranean, the sex ratio of onion thrips is 1:1 male:female (Mound 1973), markedly different from other regions of the world where males are rare (i.e., Hawaii [1:1000], Sudan [0:3000], Illinois [0 males], and Michigan [2:226]) (Quartey 1982). In Colorado, a ratio of 1:6 male:female has been reported (Kendall and Capinera 1990). In New York, although both female and male onion thrips were reported in onion fields, only females were trapped in adjacent alfalfa, clover, and wheat crops (Gangloff 1999). In this study, no male onion thrips were identified on sticky or pan traps in any year of monitoring. As well, onion thrips populations collected from both of these sites in 2000 and reared in the laboratory until 2004 did not produce any males. Therefore, based on these field and laboratory observations, it seems that in Ontario parthenogenic reproduction is the norm for onion thrips.

Plant counts provided additional insight into seasonal population density of onion thrips. Adult onion thrips never exceeded an average of 11 onion thrips per plant at either site during any field season; peak 
a)

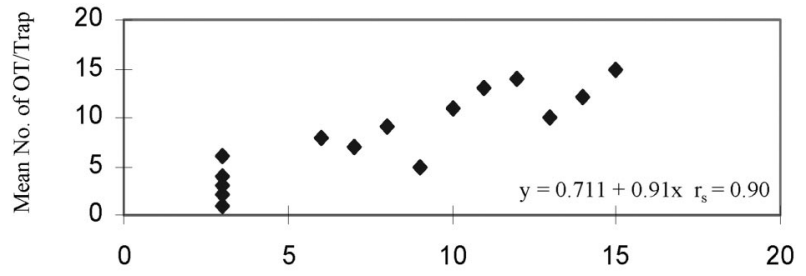

b)

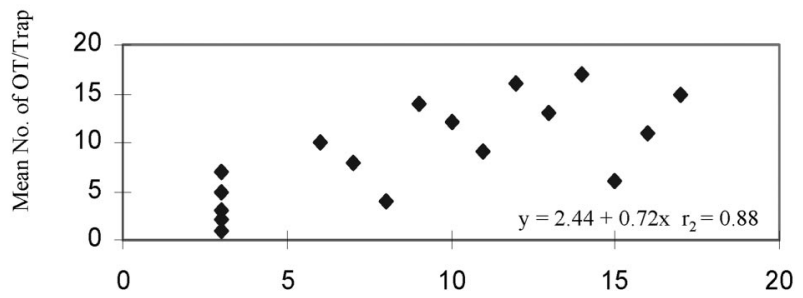

c)

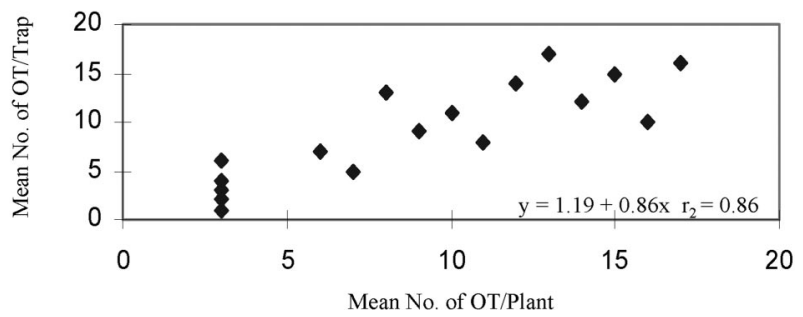

Fig. 3. Spearman rank correlation between mean trap catch and mean number of onion thrips (OT) per plant (a) in 2001 $(F=52.15 ; \mathrm{df}=1,13 ; P<0.00)$, (b) in $2002(F=16.11 ; \mathrm{df}=1,15 ; P<0.00)$; and $(\mathrm{c})$ in $2003(F=4.12 ; \mathrm{df}=1,15 ; P<$ $0.00)$.

numbers of nymphs, however, were consistently 5- to 19-fold higher than adult populations. In any year, onion thrips were not recorded on plants until $4 \mathrm{wk}$ after the first capture on sticky traps.

When traps were installed in May, onion seedlings were small (BBCH stage 100-102) (Enz and Dachler 1997). By mid-June, onion plants were larger (BBCH 103-104), with good root development. Although adult females were present in the field in mid-May, they did not seem to be feeding or sheltering on young seedlings. Lewis (1973) stated that sex, maturity, population density, weather conditions, and food quality

Table 2. Numbers of adult thrips collected on white sticky pole traps in commercial onion and adjacent soybean fields at site $\mathrm{A}$ at the Thedford-Grand Bend Marsh, Ontario, in 2002 and 2003

\begin{tabular}{|c|c|c|c|c|}
\hline \multirow{3}{*}{ Taxa } & \multicolumn{4}{|c|}{ Total no. of adult thrips captured (\% of total) } \\
\hline & \multicolumn{2}{|c|}{2002} & \multicolumn{2}{|c|}{2003} \\
\hline & Onions & Soybean & Onions & Soybean \\
\hline Thrips tabaci & $17,411(87.4)$ & $23,297(87.8)$ & $5,899(92.9)$ & $9,310(90.8)$ \\
\hline Frankliniella spp. ${ }^{a}$ & $2,016(10.1)$ & $2,393(9.0)$ & & \\
\hline F. occidentalis & & & $160(2.5)$ & $426(4.2)$ \\
\hline F. tritici & & & $97(1.5)$ & $255(2.5)$ \\
\hline Other & $503(2.5)$ & $840(3.2)$ & $193(3.1)$ & $261(2.5)$ \\
\hline Total & 19,930 & 26,530 & 6,349 & 10,252 \\
\hline
\end{tabular}

${ }^{a}$ In 2002, all Frankliniella species were grouped together. were factors influencing thrips migration. Our observations suggest that overwintered adult onion thrips entered fields early in the season but waited for some cue (s), abiotic (e.g., increased temperature) and/or biotic (e.g., host cues), before feeding and beginning reproduction on onion plants.

One potential biotic cue may be onion size. In 2003 , an insecticide trial was established in the same field where monitoring and plant counts were being conducted at site A. The onion seedlings (BBCH 102-103) used in the insecticide trial were transplanted on 21 May (MacIntyre-Allen 2004). On 17 June, 97× more onion thrips were detected on untreated onions (three- to four-leaf stage) (BBCH 103-104) in the insecticide trial then on untreated seeded onions (two- to three-leaf stage) (BBCH 102-103) in the field. On 25 and 30 June, $28 \times$ and $4 \times$ more onion thrips, respectively, were detected on untreated onions in the insecticide trial (six- to seven-leaf stage) (BBCH 106-107) versus the seeded onions (two- to four-leaf stage) (BBCH 102-104) in the same field. In addition, on these same dates, $\approx 3 \times$ more onion thrips were counted on sticky traps than on onion plants in the control treatment of the insecticide trial.

Plant counts are the most commonly recommended monitoring method for onion thrips management programs in both Canada and the United States (Shelton 
(a) 2002

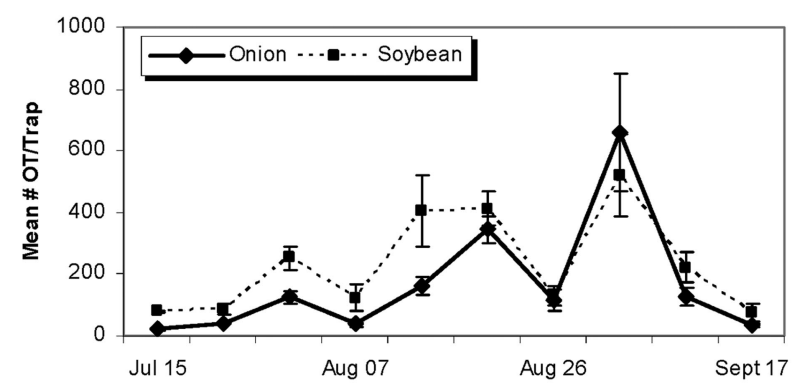

(b) 2003

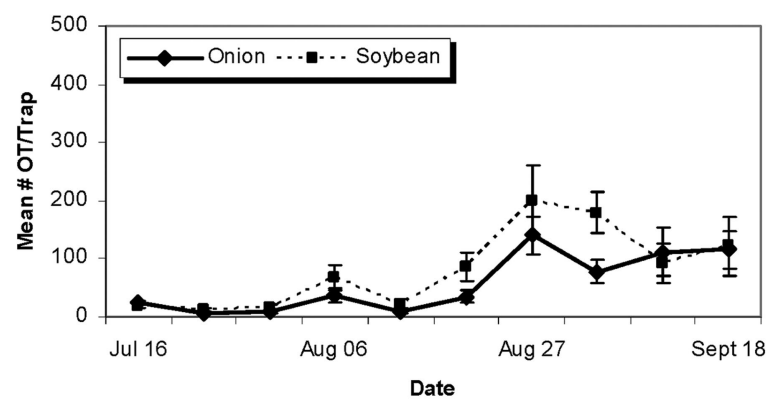

Fig. 4. Mean number of onion thrips (OT) per white sticky pole trap for each sample period in commercial onion and soybean fields at site A in (a) 2002 and (b) 2003.

et al. 1987, Edelson et al. 1989, Bird et al. 2004, OMAF 2004). In Ontario, the Ministry of Agriculture and Food recommends that onion growers monitor plants and initiate a control program when plant counts reach or exceed a threshold of three onion thrips per leaf (OMAF 2004). At site A, this threshold was not
2002

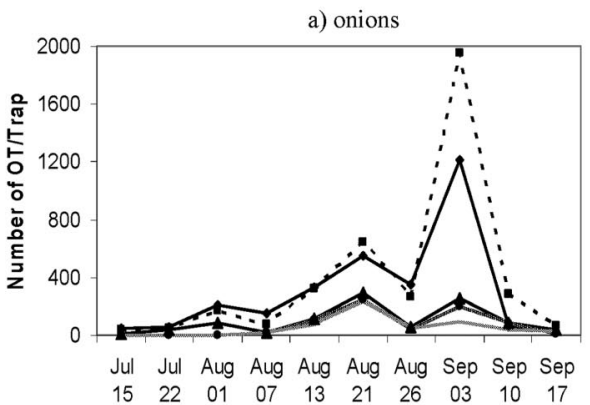

2003

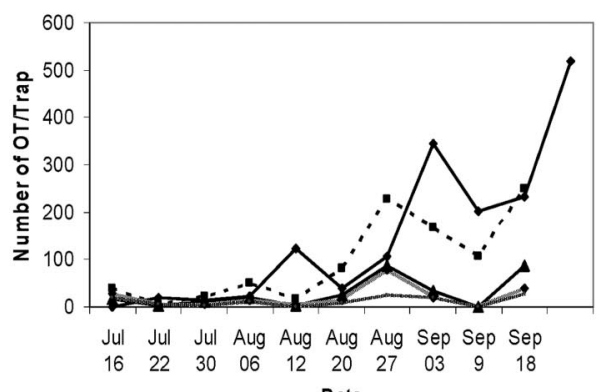

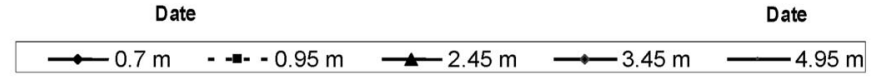
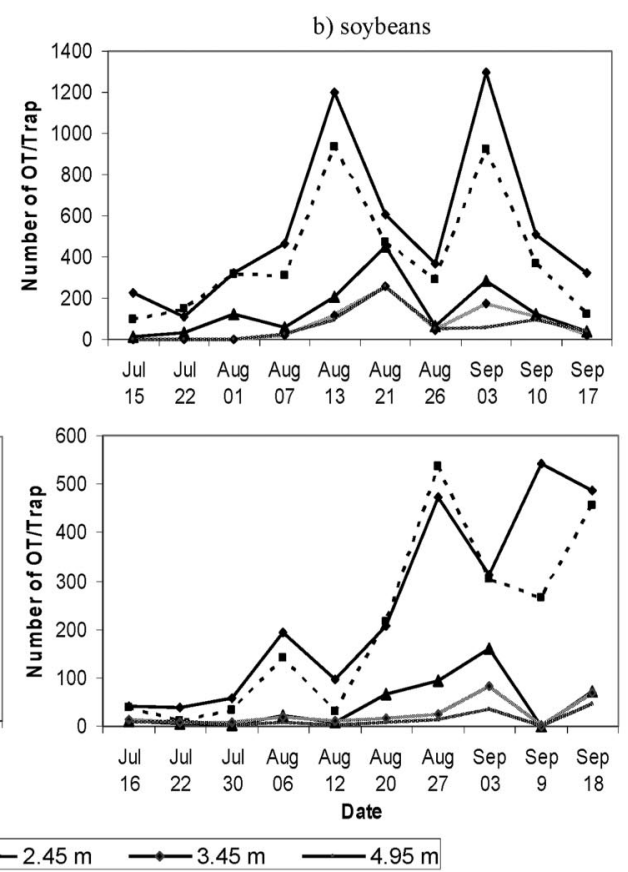

Fig. 5. Mean number of onion thrips (OT) per white sticky trap placed at different heights on a pole for each sample period in a commercial onion (a) and soybean (b) field in 2002 and 2003. 
a)

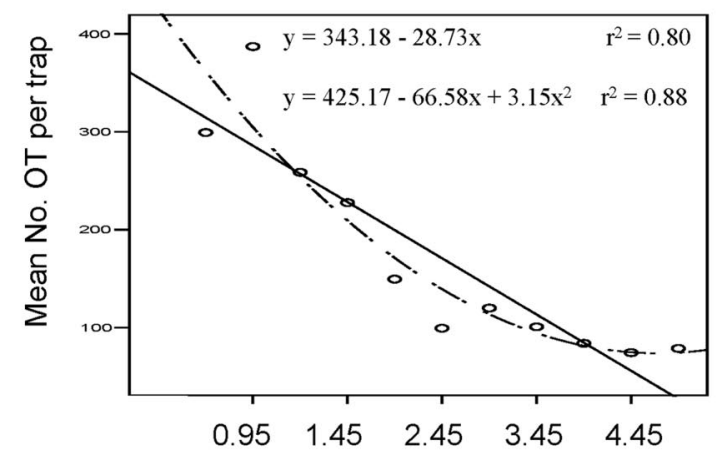

b)

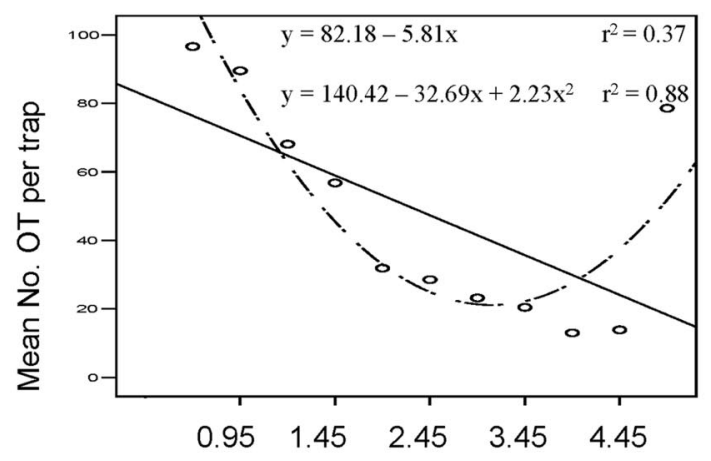

Height (m) c)

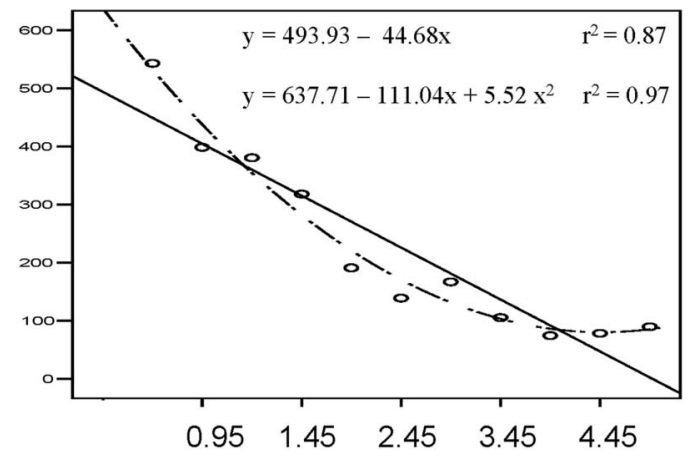

d)

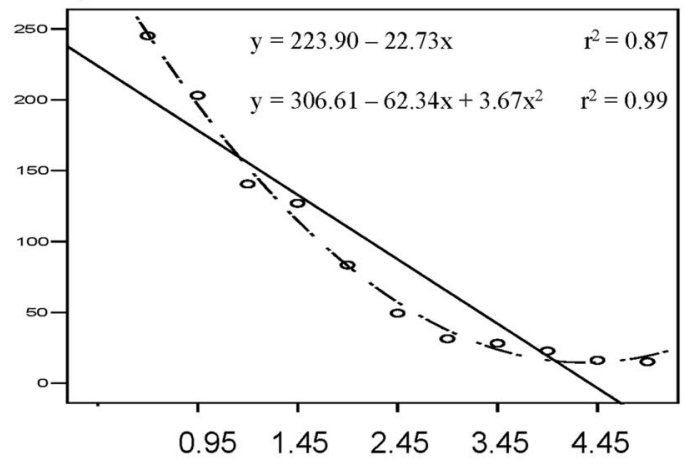

Height ( $m$ )

Fig. 6. Relationship among (a) mean number of adult onion thrips (OT) per trap versus trap height captured in a commercial onion field, 2002; (b) mean number of adult OT per trap versus trap height captured in a commercial onion field, 2003; (c) mean number of adult OT per trap versus trap height captured in an adjacent soybean field, 2002; and (d) mean number of adult OT per trap versus trap height captured in an adjacent soybean field, 2003.

reached in 2001 even though numbers on sticky traps peaked at $>950$ onion thrips per trap. A similar trend was observed in 2002. In 2003, onion thrips numbers on sticky traps exceeded 100 per trap in early July, whereas plant counts remained well below one onion thrips per leaf. Not until a second peak of 100 onion

Table 3. Confidence intervals $(95 \%)$ for quadratic regression slope parameters

\begin{tabular}{lccc}
\hline \hline Crop & Yr & Slope & $95 \%$ CI \\
\hline Onion & 2002 & $\beta_{0}$ & $-97.92 \leq \beta \leq-35.23$ \\
& & $\beta_{1}$ & $0.61 \leq \beta \leq 5.69$ \\
& 2003 & $\beta_{0}$ & $-44.48 \leq \beta \leq-20.89$ \\
Soybean & 2002 & $\beta_{1}$ & $1.27 \leq \beta \leq 3.19$ \\
& & $\beta_{0}$ & $-133.75 \leq \beta \leq-88.32$ \\
& 2003 & $\beta_{1}$ & $3.67 \leq \beta \leq 7.36$ \\
& & $\beta_{0}$ & $-65.27 \leq \beta \leq-52.88$ \\
& $\beta_{1}$ & $2.52 \leq \beta \leq 3.52$ \\
\hline
\end{tabular}

Also see Fig. 6. thrips per trap was recorded in early August was the plant threshold exceeded. At site B, the population peaked on sticky traps and reached the threshold during the same week in both 2001 and 2002. In 2003, the population peaked on sticky traps mid-August, whereas the threshold was not reached until the first week of September. This relatively long lag period when high numbers of onion thrips were captured on sticky traps and when plant numbers reached the threshold indicates that plant counts alone may not be the best monitoring method for Ontario onion growers. Additionally, sticky traps provided an early warning of the arrival and buildup of populations in the onion field. A statistical comparison of onion thrips numbers on sticky traps and plants revealed that the two sampling methods were positively correlated. Sticky traps could be introduced into monitoring programs to monitor the seasonal population dynamics of onion thrips. Because our results also indicated that, on average, most onion thrips fly between 0.7 and 
$0.95 \mathrm{~m}$ above the ground regardless of the crop or the year, sticky traps installed at these heights could effectively monitor onion thrips populations in the field.

In conclusion, our research indicates that female onion thrips are the predominant species of thrips captured with sticky or pan traps in Ontario onion fields. Populations of adult onion thrips have two major peaks during the Ontario growing season. Adults arrive in fields mid-May, build to high numbers by mid-July, and peak in late August. Plant monitoring within the field demonstrated that early plant populations are predominantly composed of adults with nymphal populations dominating the remainder of the growing season (mid-July to early September). Pole trap data revealed that the majority of adult onion thrips are active $0.7-0.95 \mathrm{~m}$ above the ground. Early season monitoring with white sticky traps placed $0.7 \mathrm{~m}$ above the ground would allow onion growers to identify developing onion thrips populations and initiate control tactics to reduce overall onion thrips numbers and minimize population peaks mid-to-late August.

\section{Acknowledgments}

We thank Ted Sawinski for advice and help in conducting this study, Becki Dries for field assistance, and G. Umphrey for statistical expertise. We also thank the growers at the Thedford-Grand Bend Marsh who allowed us to monitor in their fields. This work was funded by: Ontario Fruit and Vegetable Growers' Association; Thedford-Grand Bend Marsh Vegetable Growers' Association; the Matching Investment Initiatives Program of Agriculture and Agri-Food Canada; Food Systems 2002 of the Ontario Ministry of Agriculture and Food (OMAF); and the University of GuelphOMAF Plants Program.

\section{References Cited}

Bird, G., B. Bishop, E. Grafius, M. Hausbeck, J. Lynnae, K. William, and W. Pett. 2004. Insect, diseases and nematode control for commercial vegetables, pp. 81-82. Mich. State Univ. Ext. Bull. E-312. (web4.msue.msu.edu/ veginfo/bulletins/E312/index.htm)

Boyce, K. E., and L. A. Miller. 1954. Overwintering habitats of the onion thrips, Thrips tabaci Lind. (Thysanoptera: Thripidae) in southwestern Ontario. Rep. Entomol. Soc. Ont. 84: 82-86.

Brewster, J. L. 1994. Onions and other vegetable alliums. CAB International, Oxon, United Kingdom.

Chiasson H. 1986. A synopsis of the Thysanoptera (thrips) of Canada. Lyman Entomological Museum and Research Laboratory. Memoir No. 17.

Cho, K., C. S. Eckel, J. F. Walgenbach, and G. C. Kennedy. 1995. Overwintering of thrips (Thysanoptera: Thripidae) in North Carolina. Environ. Entomol. 24: 58-67.

Coudriet, D. L., A. N. Kishaba, J. D. McCreight, and G. W. Bohn. 1979. Varietial resistance in onions to thrips. J. Econ. Entomol. 72: 614-615.

Edelson, J. V., B. Cartwright, and T. A. Royer. 1989. Economics of controlling onion thrips (Thysanoptera: Thripidae) on onions with insecticides in south Texas. J. Econ. Entomol. 82: 561-564.

Enz, M., and C. Dachler. 1997. Compendium of growth stage identification keys for mono- and dicotyledonous plants. Extended BBCH Scale. A joint publication of BBA, BSA, IGZ, IVA, AgrEvo, BASF, Bayer and Novartis, 2nd ed.www.ersaf.lombardia.it/suoliagrometeo/agro-meteo/ download/scaleBBCH.pdf.

Fournier, F., G. Boivin, and R. K. Stewart. 1995. Effect of Thrips tabaci (Thysanoptera: Thripidae) on yellow onion yields and economic thresholds for its management. J. Econ. Entomol. 88: 1401-1407.

Gangloff, J. L. 1999. Population dynamics and insecticide resistance of onion thrips, Thrips tabaci Lindeman (Thysanoptera: Thripidae) in onions. Ph.D. dissertation, Cornell University, Ithaca, NY.

Kendall, D. H., and J. L. Capinera. 1987. Susceptibility of onion growth stages to onion thrips (Thysanoptera: Thripidae) damage and mechanical defoliation. Environ. Entomol. 16: 859-863.

Kendall, D. H., and J. L. Capinera. 1990. Geographic and temporal variation in the sex ratio of onion thrips. Southwest. Entomol. 15: 80-88.

Lewis, T. 1973. Thrips, their biology, ecology and economic importance. Academic, London, United Kingdom.

Lu, F. M. 1990. Color preference and using silver mulches to control onion thrips, Thrips tabaci Lindeman. Chin. J. Entomol. 10: 337-342.

MacIntyre-Allen, J. K. 2004. Population dynamics, insecticide resistance and management of onion thrips, Thrips tabaci Lindeman, in southwestern Ontario. Ph.D. dissertation, University of Guelph, Ontario, Canada.

Mayer, D. F., D. Lunden, and L. Rathbone. 1987. Evaluation of insecticides for Thrips tabaci (Thysanoptera: Thripidae) and effects of thrips on bulb onions. J. Econ. Entomol. 80: 930-932.

McKinlay, R. G. 1992. Vegetable crop pests. CRC, Boca Raton, FL.

Mound, L. A. 1973. Thrips and whitefly, pp. 230-232. In A. J. Gibbs [ed.], Viruses and Invertebrates. North-Holland Publishing Company, New York.

Mound, L. A., and G. Kibby. 1998. Thysanoptera: an identification guide. CAB International, Oxon, United Kingdom.

Neter J., and W. Wasserman. 1974. Applied linear statistical models. Richard D. Irwin, Inc., Homewood, IL.

[OMAF] Ontario Ministry of Agriculture and Food. 2004. Vegetable production recommendations-2004-2005. Publication 363. Queen's Printer for Ontario, Toronto, Ontario, Canada.

Palmer J. M., L. A. Mound, and G. J. Du Heaume. 1989. Thysanoptera. In C. R. Bretts [ed.], CIE guides to insects of importance to man. CAB International, Wallingford, United Kingdom.

Quartey, S. Q. 1982. Population dynamics of the onion thrips, Thrips tabaci Lind., on onions (Michigan). Ph.D. dissertation, Michigan State University, East landing, MI

Richter E., M. Hommes, and J.-H. Krauthausen. 1999. Investigations on the supervised control of Thrips tabaci in leek and onion crops. Integrated control in field vegetable crops. IOBC Bull. 22: 61-72.

Shelton, A. M., J. P. Nyrop, R. C. North, C. Petzoldt, and R. Foster. 1987. Development and use of a dynamic sequential sampling program for onion thrips, Thrips tabaci (Thysanoptera: Thripidae), on onions. J. Econ. Entomol. 80: 1051-1056.

SPSS Inc. 2004. SPSS for Windows. User's manual, version 12.0 Statistical Package for the Social Sciences. SPSS Inc., Chicago, IL. 
Statistix. 2000. Statistix for Windows. User's manual, version 2.2. Statistix, Talhassee, FL.

Theunissen, J., and H. Legutowska. 1991. Thrips tabaci Lindeman (Thysanoptera: Thripidae) in leek: within plant distribution. J. Appl. Entomol. 112: 309-316.

Tolman, J. H., D.G.R. McLeod, and C. R. Harris. 1986. Yield losses in potatoes, onions and rutabagas in southwestern
Ontario, Canada -the case for pest control. Crop Prot. 5: 227-237.

Van de Steene, F. 1999. Monitoring and control of Thrips tabaci Lind. with furathiocarb in leek fields. Integrated control in field vegetable crops. IOBC Bull. 22: 235-240.

Received 21 September 2004; accepted 24 June 2005. 